\title{
Was Level of Fear of Recurrence Associated with Level of Fatigue in Colorectal Cancer Patients?
}

\author{
Shiow-Ching Shum, RN, PhD; Yun-Jen Chou, RN, MSN, Hsuan-Ju Kuo, RN, MSN, \\ School of Nursing, College of Medicine, National Taiwan University, Taipei, Taiwan
}

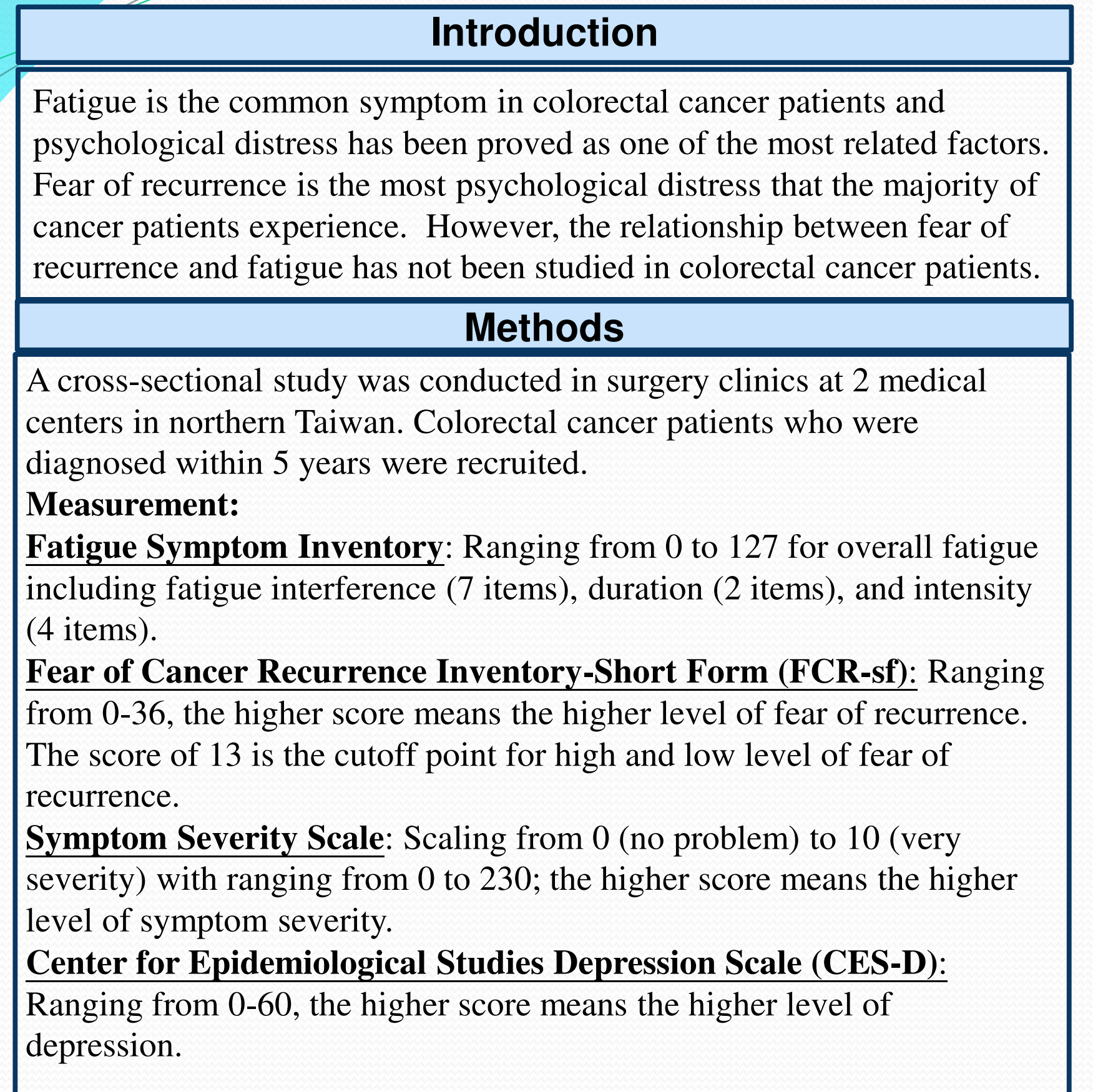

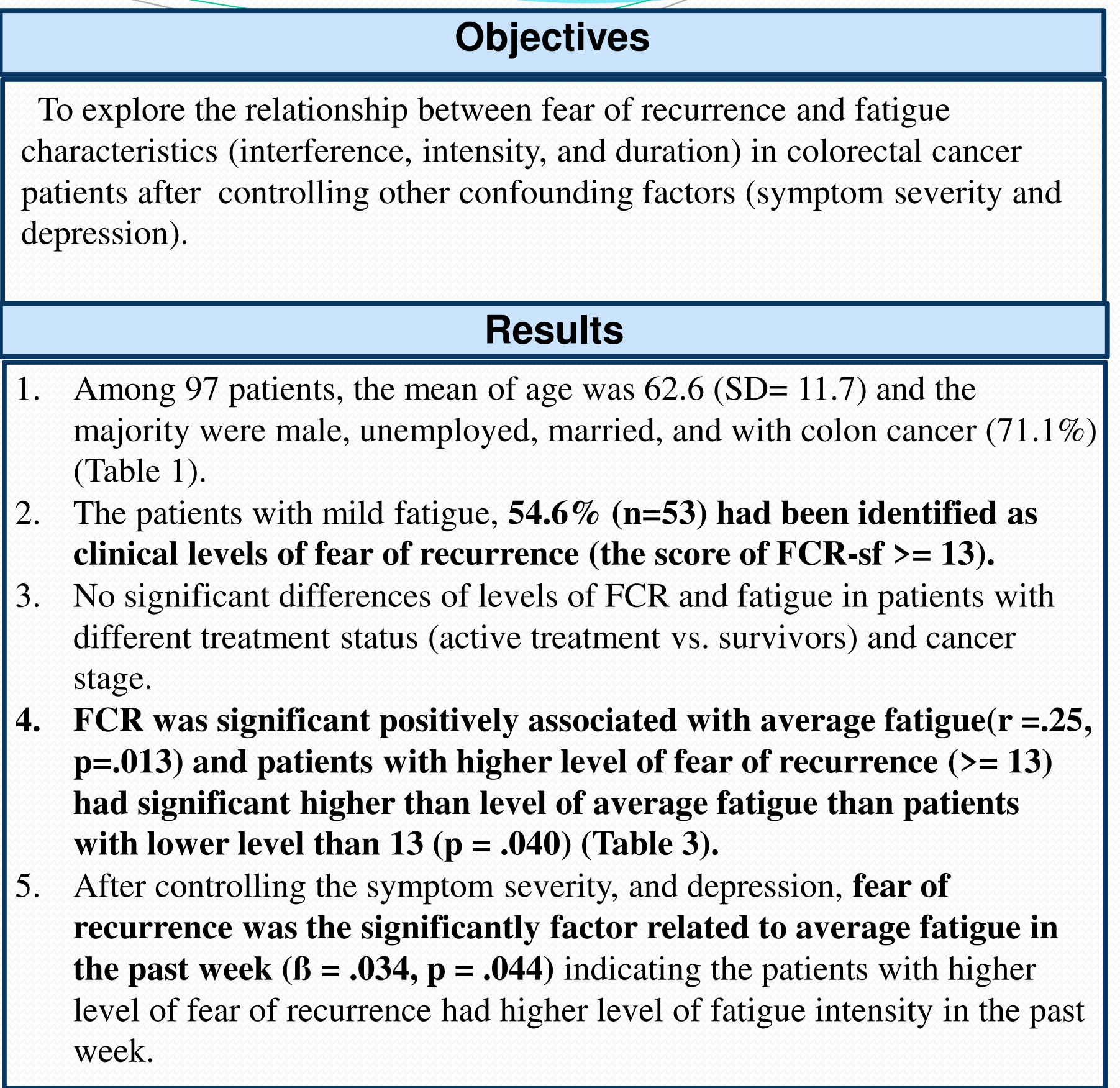

Table 1 Clinical Disease Characteristics $(N=97)$

\begin{tabular}{|l|c|c|}
\hline \multicolumn{1}{|c|}{ Characteristics } & n & \% \\
\hline Functional status & & \\
\hline loo & 18 & 18.6 \\
\hline $\mathbf{9 0}$ & 73 & 75.3 \\
\hline $\mathbf{8 o}$ & 6 & 6.2 \\
\hline Diagnosis & & \\
\hline Colon cancer & 69 & 71.1 \\
\hline Rectal cancer & 28 & 28.9 \\
\hline Stage & & \\
\hline I & 38 & 39.2 \\
\hline II & 30 & 30.9 \\
\hline III & 29 & 29.9 \\
\hline Chronic disease & & \\
\hline No & 45 & 46.4 \\
\hline Yes & 52 & 53.6 \\
\hline $\begin{array}{l}\text { Diagnose time } \\
\text { (Month) (Mean/SD) }\end{array}$ & 27.9 & 16.8 \\
\hline $\begin{array}{l}\text { End of treatment } \\
\text { (Month) (Mean/SD) }\end{array}$ & 20.9 & 17.1 \\
\hline
\end{tabular}

Table 2 Mean Scores of Fatigue Characteristics, Symptom Distress, Depression, and Fear of Recurrence

\begin{tabular}{|l|c|c|}
\hline \multicolumn{1}{|c|}{ Scales } & M & SD \\
\hline Overall Fatigue & 7.1 & 14.3 \\
\hline $\begin{array}{c}\text { Interference } \\
\text { caused by fatigue }\end{array}$ & 2.2 & 6.6 \\
\hline Intensity & 2.8 & 5.3 \\
\hline Duration & 2.1 & 3.8 \\
\hline Average fatigue & 0.8 & 1.5 \\
\hline Symptom Severity & 12.5 & 14.9 \\
\hline Depression & 6.7 & 7.1 \\
\hline Fear of recurrence & $\mathbf{1 2 . 7}$ & 7.8 \\
\hline
\end{tabular}

Table 3 Correlation among Fear of Recurrence, Fatigue, Symptom Severity, and Depression

\begin{tabular}{|l|c|c|c|c|}
\hline & $\begin{array}{c}\text { All } \\
(\mathbf{N = 9 7 )} \\
\mathbf{r}\end{array}$ & $\begin{array}{c}\frac{\text { Low Group }}{(\mathbf{n}=\mathbf{4 4})} \\
\mathbf{M ( S D )}\end{array}$ & $\begin{array}{c}\text { High Group } \\
\frac{\mathbf{( n = 5 3 )}}{\mathbf{M}(\mathbf{S D})}\end{array}$ & $\mathbf{p}^{\mathbf{a}}$ \\
\hline FSI & .190 & $5.39(14.43)$ & $8.51(14.12)$ & .286 \\
\hline $\begin{array}{l}\text { Interference } \\
\text { caused by } \\
\text { fatigue }\end{array}$ & .126 & $1.93(6.59)$ & $2.47(6.58)$ & .689 \\
\hline Intensity & $.239 *$ & $1.77(4.55)$ & $3.66(5.79)$ & .076 \\
\hline Duration & .161 & $1.68(4.00)$ & $2.38(3.68)$ & .375 \\
\hline $\begin{array}{l}\text { Average } \\
\text { fatigue }\end{array}$ & $\mathbf{. 2 5 0 *}$ & $0.48(1.25)$ & $1.09(1.67)$ &. $\mathbf{0 4 0}$ \\
\hline $\begin{array}{l}\text { Symptom } \\
\text { severity }\end{array}$ & .126 & $10.70(15.93)$ & $12.40(12.46)$ & .559 \\
\hline Depression & $.339 * *$ & $4.93(7.01)$ & $8.21(6.83)$ & $\mathbf{. 0 2 2}$ \\
\hline
\end{tabular}

Note: ${ }^{*} \mathrm{p}<0.05,{ }^{* *} \mathrm{p}<0.01,{ }^{* * *} \mathrm{p}<0.001$. High group patients was identified as those score of fear of recurrence $\geq 13$ and the low group patients with the score of fear of recurrence $<13 .{ }^{a} \mathrm{p}$ values were the results of student $t$-test to examine the differences between the two groups.

Table 4 Examining the associated factors with Overall and Average Fatigue in the Generalized Estimating Equations Analysis ${ }^{a}$

\begin{tabular}{|l|c|c|c|c|c|c|c|c|}
\hline \multirow{2}{*}{\multicolumn{1}{c}{ Variable }} & \multicolumn{3}{c|}{ Overall Fatigue } & \multicolumn{3}{c|}{ Average Fatigue } \\
\cline { 2 - 9 } & Coefficient & Std. Err. & $\begin{array}{c}\text { Wald chi- } \\
\text { square }\end{array}$ & $\mathrm{p}$ & Coefficient & Std. Err. & $\begin{array}{c}\text { Wald chi- } \\
\text { square }\end{array}$ & \begin{tabular}{c} 
p \\
\hline Symptom severity
\end{tabular} \\
\hline Depression & .635 & .112 & 31.980 & .061 & .056 & .010 & 30.055 & .000 \\
\hline Fear of recurrence & .193 & .242 & .639 & .000 & .006 & .023 & .077 & .781 \\
\hline Intercept & -144 & .137 & 1.104 & .424 & .034 & .017 & 4.041 & .044 \\
\hline
\end{tabular}

Note: ${ }^{\text {a }}$ Generalized estimating equation was based on unstructured working correlation matrix.

\section{Conclusions}

Colorectal cancer patients with higher level of fear of recurrence had the higher level of fatigue in average. Therefore, decreasing the level of fear of recurrence might be an important factor to help colorectal cancer patients in managing fatigue effectively. However, their causal effect needs to identify in the further study with larger sample size.

\section{Acknowledgement}

The authors gratefully acknowledge the assistance of the patients who participated in this study and for the grant support from Ministry of Science and Technology (MOST104-2314-B-002-097-MY3).

\section{References}

Fardell, J. E., Jones, G., Smith, A. B., Lebel, S., Thewes, B., Costa, D., . . Butow, P. (2017). Exploring the screening capacity of the Fear of Cancer Recurrence Inventory-Short Form for clinical levels of fear of cancer recurrence. Psychooncology. doi: 10.1002/pon.4516 